\title{
Knowledge and Practice of Dietary Recommendations among Cardiovascular Disease Patients Attending Ngaoundere Regional Hospital, Adamawa Region, Cameroon
}

\author{
Olivier M. Pancha ${ }^{1,{ }^{*}}$, Marcel T. Tamanji ${ }^{2}$, Joseph Mtsavara ${ }^{2}$, Laure S.B. Bouagni ${ }^{1}$, \\ Jacques O. Ngoufack ${ }^{1}$ and Clergé Tchiegang ${ }^{3}$
}

${ }^{1}$ Department of Biomedical Sciences, Faculty of Science, University of Ngaoundere, PO Box 454, Ngaoundere, Cameroon

${ }^{2}$ Clinical Laboratory Service, Ngaoundere Regional Hospital, PO Box 45, Ngaoundere, Cameroon

${ }^{3}$ Laboratory of Bio-processes, Research Unit of Biochemistry, Food Technology and Nutrition, University of Ngaoundere, PO Box 454, Ngaoundere, Cameroon

\begin{abstract}
Objective: To assess the level of awareness and adherence of patients to dietary recommendations in the management of Cardiovascular Diseases (CVDs).

Methods: This cross-sectional study included CVD patients on medical visits at the cardiology unit of Ngaoundere Regional Hospital. Well informed and consenting participants filled a pre-tested questionnaire on dietary knowledge and practice.

Results: 129 patients were retained in this study out of 151 enrolled. $58.9 \%$ of participants knew that the consumption of vegetables is beneficial for their status. Fruit consumption recorded the same level of awareness. All other dietary variables studied revealed less than $50 \%$ level of awareness among participants. Concerning recommended dietary practices, $73.64 \%$ of participants consumed oils rich in saturated fatty acids. Meat and fish consumption were recorded at $62.01 \%$ and $65.12 \%$ respectively, with a $94.57 \%$ preference to red meat consumption. Almost $19.38 \%$ of the study population consumed eggs more than 3 times per week, $31.78 \%$ and $41.09 \%$ consumed vegetables and fruits at least thrice and twice a week respectively. The overall mean adherence to the studied cardiovascular disease dietary recommendations was $38.31 \%$, with only fish, vegetable and tea/coffee recommendations recording adherences of $50 \%$ and above.

Conclusion: The findings demonstrate a low level of awareness and adherence to dietary recommendations in the management of CVDs, thus the need for the strengthening of health promotion programs and improvement of the
\end{abstract} nutritional advices in our context.

Keywords: Cameroon, Ngaoundere Regional Hospital, Cardiovascular diseases, Diet, Knowledge, Practice.

\section{INTRODUCTION}

The World Health Organization (WHO) defines Cardiovascular Diseases (CVDs) as a set of disorders affecting the heart and blood vessels [1]. Currently, CVDs are the leading cause of death worldwide with an estimated 17.5 million global CVD deaths, accounting for $31 \%$ of global deaths, with 7.4 million deaths for coronary heart disease and 6.7 million deaths from stroke [1-3]. According to the WHO, if appropriate measures are not taken to curb these CVD trends, about 23.6 million people will die of cardiovascular disease by 2030 [1]. Cameroon is no exception, as these diseases are rapidly gaining grounds as a major leading cause of mortality and disability among other noncommunicable diseases with a prevalence rate varying between $9 \%$ and $11 \%$ depending on authors [ 4 , 5].

*Address correspondence to this author at the Department of Biomedical Sciences, Faculty of Science, University of Ngaoundere, PO Box 454, Ngaoundere, Cameroon; Tel: (237) 674982237;

E-mail: olivier_pancha@yahoo.fr
Simultaneously with CVDs, cardiovascular disease risk factors such as diabetes, obesity, physical inactivity and poor dietary are increasing, with the Cameroonian population thus progressively becoming more prone to cardiovascular events [6-8]. In Ngaoundere, CVDs have been reported to be the most important causes of admissions from noncommunicable diseases in hospital setting, their nosological forms being dominated by hypertension, heart failure and stroke [5].

It has been shown that, a diet rich in saturated fats and poor in fruits and vegetables, increase the risk of cardiovascular events [9]. Consequently, the management of heart disease should not only entail pharmacologic methods in controlling cardiovascular risk, but also by encouraging adequate and appropriate nutrition and lifestyle modification with the goal of preventing the occurrence of CVD complications [10]. Health promotion programs have previously been implemented in our context and the country at large, but without any previous data on the level of 
awareness and dietary adherence. The objective of this work was to determine, in the case of patients under follow-up in the Ngaoundere Regional Hospital, the level of dietary awareness and assess the degree of adherence to dietary recommendations in patients with CVDs in view of contributing relevant data for evidencebased decision making towards strengthening of health promotion programs and consequently CVD management.

\section{METHODS}

\section{Study Area}

The study was carried out from June to September 2015 at the Ngaoundere Regional Hospital. This is the reference healthcare institution of the Adamawa Region in Cameroon, located in Ngaoundere city, the administrative headquarters of the region. Geographically, the Adamawa region of Cameroon is neighbors to the Nigeria and Central African Republic respectively. Economically, this region depends on cattle rearing, while crops like millet, maize, groundnuts, cassava, yams and cocoyams are mostly cultivated on subsistence levels [11].

\section{Study Design, Population and Sample Size}

This cross-sectional study involved a random and progressive selection of participants which included patients previously or currently diagnosed with any form of CVDs at the Ngaoundere Regional Hospital. Nosological forms of CVDs encountered comprised of hypertension, stroke, lower extremity artery disease, cardiac insufficiency, and angina pectoris.

The sample size of this study was estimated with the help of the Lorenz formula [12]:

$$
\mathrm{N}=\left[\mathrm{p} . \mathrm{q}\left(\mathrm{z}_{\alpha}\right)^{2}\right] / \mathrm{d}^{2}
$$

Where: $\mathrm{N}=$ sample size; $\mathrm{p}=$ prevalence of CVDs in a hospital milieu in Adamawa, 9.9\%; q=1-p, 90.1\%; $d=$ error margin, $5 \%$; $Z_{\alpha}=Z$-score, 1.96 for $95 \%$ confidence level.

\section{Inclusion criteria}

Patients were enrolled if they had either a previous or current diagnosis of any form of CVDs, attended the Ngaoundere Regional Hospital and consented in writing to participate in this study.

\section{Exclusion criteria}

Patients suffering from CVDs who refused to sign a written consent form were excluded from this study.

\section{Study Variables}

Parameters considered in this work comprised of sociodemographic characteristics including, age, gender, marital status, level of education, profession and religion. Dietary knowledge and practice the same as the level of adherence to dietary recommendations were also studied.

\section{Data Collection}

Data were collected with the help of a pre-tested questionnaire following a one-on-one encounter with each participant. Participants who could read and write, self-responded and completed the questionnaire, while those who could not, were aided by any of the investigators, with communication done in their mother tongue. The French, English and Fulfulde (traditional) languages were the principal languages of communication.

The questionnaire consisted of identification of participants, awareness on cardiovascular disease risk factors and dietary habits. It was established according to the nutrients of interest and with respect with the food habits of the participants. The frequencies of consumption were recorded as number of times per day or week. Each participant was expected to choose the frequency closest to his/her usual level of consumption for each food type.

Knowledge and practice were studied to determine whether the implementation of dietary recommendations was related to the knowledge on food factors, and secondly to deduce the level of dietary adherence. The questionnaire consisted of a set of questions on knowledge and practice of certain dietary habits to which individuals had to answer "yes" or "no".

Dietary recommendations were adapted from the Capital Health-Food and Nutrition service's heart healthy eating tips [13]. Practice of dietary recommendations was accorded a "yes" response when:

Fish consumption was at least twice per week;

Fruit consumption was at least twice per week;

Vegetable consumption was at least thrice a week;

Legume consumption was at least thrice a week;

Tea/coffee consumption was at most 3 cups daily;

Meat consumption was at most twice a week; 
Participant consumed white meat and oils rich in unsaturated fatty acids;

Participant did not consume oils rich in saturated fatty acids;

Level of adherence was calculated in accordance with the propositions of Avira and Sabin [14] as follows: Level of Adherence $=\left(K_{p} \times 100\right) /\left(K_{P}+K_{N P}\right)$

Where $\mathrm{K}_{\mathrm{p}}=$ Knowledge and practice, $\mathrm{K}_{\mathrm{NP}}=$ Knowledge without practice

\section{Ethical Considerations}

Administrative and ethical clearances were obtained from the Ngaoundere University (Ref: 2015/158/UN/ DFS/CD-SBM) and the ethical committee of the Ngaoundere Regional Hospital (Ref: 1078/L/RC/RA/ DSP/HR/NGD/CLE) respectively. Participation was voluntary and discontinuity of participation free without any form sanction or discrimination. Patient data obtained were treated confidentially.

\section{Data management and Analysis}

Data were collected, registered, and processed using Microsoft Excel 2013 spreadsheets. Data were presented principally as percentages with the Chisquare test used to determine association between knowledge and practice of dietary recommendations.

\section{RESULTS}

\section{General Characteristics of Study Population}

Some general characteristics of the study population are presented in Table 1.

Out of 151 persons recruited, a total of 129 persons met out inclusion criteria, 65 (50.39\%) males and 64 $(49.61 \%)$ females recording a 1.01 sex ratio $(M / F)$. The age of study participants ranged from 27 to 89 years with mean age being $56.68 \pm 12.34$ years. Following age stratification, the age group $55-75$ years $(55,03 \%)$ was the most represented. A majority of the study population was married $(77.52 \%)$. Compared to a wide range of other occupations encountered, the study recorded a vast predominance of housewives (42.64\%). Regarding the educational levels, it was observed that $68.22 \%$ of the participants had acquired less than a secondary level education. Furthermore, Muslim faithfuls constituted about two-thirds of the study population compared to their Christian counterparts.
Table 1: General Characteristics of Study Population

\begin{tabular}{|c|c|c|}
\hline Variables & Total & $\begin{array}{l}\text { Proportions of total } \\
\text { population (\%) }\end{array}$ \\
\hline \multicolumn{3}{|l|}{ Age (years) } \\
\hline$\leq 35$ & 7 & 5.43 \\
\hline $36-55$ & 44 & 34.11 \\
\hline $56-75$ & 71 & 55.04 \\
\hline$>75$ & 7 & 5.43 \\
\hline \multicolumn{3}{|l|}{ Marital Status } \\
\hline Unmarried & 7 & 5.43 \\
\hline Married & 100 & 77.52 \\
\hline Widowed & 16 & 12.40 \\
\hline Divorced & 6 & 4.65 \\
\hline \multicolumn{3}{|l|}{ Profession } \\
\hline Farmers & 11 & 8.53 \\
\hline Traders & 12 & 9.30 \\
\hline Housewives & 55 & 42.64 \\
\hline Salary earners (formal) & 20 & 15.50 \\
\hline Retired workers & 12 & 9.30 \\
\hline Others (informal) & 19 & 14.73 \\
\hline \multicolumn{3}{|l|}{ Level of Education } \\
\hline Uneducated & 62 & 48.06 \\
\hline Primary & 26 & 20.16 \\
\hline Secondary & 35 & 27.13 \\
\hline Higher & 6 & 4.65 \\
\hline \multicolumn{3}{|l|}{ Religion } \\
\hline Christian & 44 & 34.11 \\
\hline Muslim & 85 & 65.89 \\
\hline
\end{tabular}

\section{Selected Dietary Patterns of Participants}

Results of selected dietary pattern of study participants can be seen in detail in Table 2 .

It was recorded that $73.64 \%$ of participants consumed oils rich in saturated fatty acids. Meat consumption (mainly cow meat) was frequent among participants with $62.01 \%$ consuming more than twice a week. In addition, participants $(94.57 \%)$ predominantly practiced red meat consumption. Weekly fish consumption of at least twice was estimated at $65.12 \%$. We went further to examine the frequency of consumption of eggs, vegetables and fruits per week. We recorded the following: while $19.38 \%$ of the study population consumed eggs more than 3 times a week, $31.78 \%$ consumed vegetables at least thrice weekly and $41.09 \%$ ate fruits at least twice weekly. We also 
Table 2: Distribution of Dietary Habits of Study Participants

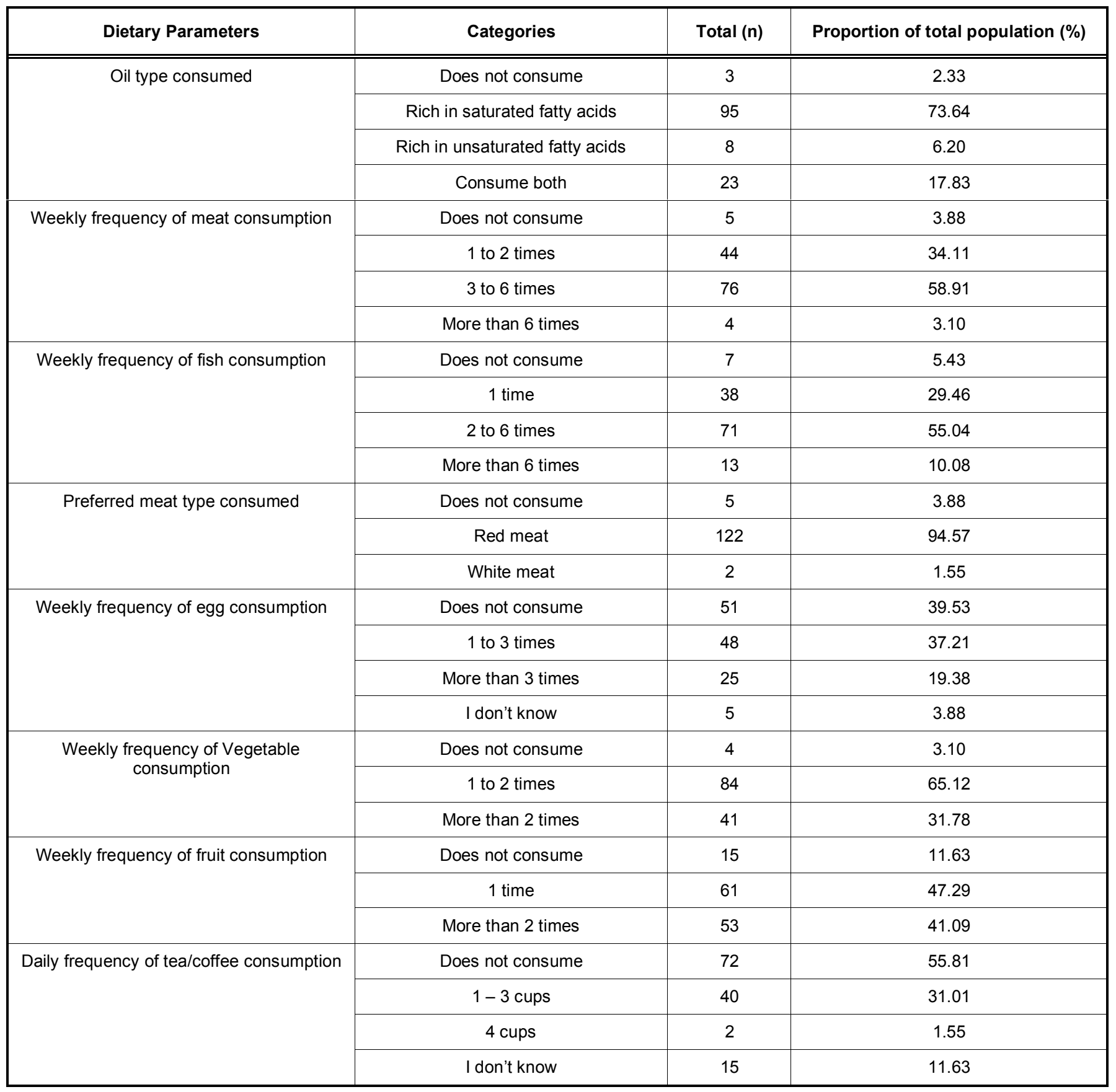

took into effect records of tea/coffee consumption and recorded a $32.56 \%$ daily consumption of at least a cup.

\section{Knowledge and Practice of Dietary Recommendations in CVD Management}

Participants were interrogated on selected dietary recommendations in CVDs in a bid to assess their level of awareness and knowledge on the subject. Apart from the knowledge on the fact that vegetables possess beneficial characteristics, the level of awareness on the contribution of fish ( $29 \%$ compared to meat in general), tea/coffee consumption (31\%), type of meat $(5 \%)$ and oils $(9 \%)$ consumed was generally low.

In order to ascertain "true" awareness on dietary recommendations for the management of CVDs, participants' knowledge was subsequently evaluated based on their implementation of selected recommended dietary practice (knowledge and practice). With the exception of the encouragement of the consumption of vegetables, every other 
Table 3: Association between Knowledge and Practice on the Consumption of some Selected Foods

\begin{tabular}{|c|c|c|c|c|c|}
\hline $\begin{array}{c}\text { Do you know the consumption } \\
\text { of: }\end{array}$ & & \multicolumn{2}{|c|}{ Do you practise it? } & $\begin{array}{l}\text { Total } \\
\mathbf{n}(\%)\end{array}$ & P-value \\
\hline \multirow{3}{*}{$\begin{array}{l}\text { Oils rich in saturated fats is } \\
\text { discouraged? }\end{array}$} & Yes n (\%) & $9(7.0)$ & $24(18,6)$ & $33(25.6)$ & \multirow[t]{3}{*}{0,001} \\
\hline & No n (\%) & $2(1.6)$ & $94(72.9)$ & $96(74.4)$ & \\
\hline & Total & $11(8.5)$ & 118(91.5) & $129(100)$ & \\
\hline $\begin{array}{l}\text { Oils rich in unsaturated fats is } \\
\text { encouraged? }\end{array}$ & Total & $11(8.5)$ & $118(91.5)$ & $129(100)$ & 0,001 \\
\hline \multirow[t]{2}{*}{ Meat in general is discouraged? } & Yes n (\%) & $26(20.2)$ & $27(20.9)$ & $53(41.1)$ & \multirow[t]{2}{*}{0,030} \\
\hline & No n (\%) & $23(17.8)$ & $53(41.1)$ & $76(58.9)$ & \\
\hline White meat is advised? & Total & $20(15,5)$ & $109(84,5)$ & $129(100)$ & 0,015 \\
\hline \multirow{3}{*}{$\begin{array}{l}\text { Red meat frequently is } \\
\text { discouraged? }\end{array}$} & Yes n (\%) & $5(3.9)$ & $12(9.3)$ & $17(13.2)$ & \multirow[t]{3}{*}{0.002} \\
\hline & No n (\%) & $7(5.4)$ & $105(81.4)$ & $112(86.8)$ & \\
\hline & Total & $12(9,3)$ & $117(90,7)$ & $129(100)$ & \\
\hline \multirow[t]{3}{*}{ Fish is encouraged? } & Yes n (\%) & $29(22.5)$ & $24(18.6)$ & $53(41.1)$ & \multirow[t]{3}{*}{0.038} \\
\hline & No n (\%) & $55(4 ., 6)$ & $21(16.3)$ & $76(58.9)$ & \\
\hline & Total & $84(65.1)$ & $45(34.9)$ & $129(100)$ & \\
\hline Vegetables are encouraged? & Yes n (\%) & $51(39.5)$ & $25(19.4)$ & $76(58.9)$ & 0.078 \\
\hline \multirow[t]{3}{*}{ Tea/Coffee is discouraged? } & Yes n (\%) & $31(24,0)$ & $15(11,6)$ & $46(35,7)$ & \multirow[t]{3}{*}{0,049} \\
\hline & No n (\%) & $41(31,8)$ & $42(32,6)$ & $83(64,3)$ & \\
\hline & Total & $72(55,8)$ & $57(44,2)$ & $129(100)$ & \\
\hline
\end{tabular}

recommended dietary practice recorded low levels of "true" awareness (Table 3).

\section{Level of Dietary Adherence}

The individual and mean adherence levels for the dietary recommendations studied are presented in Figure 1.

It was important to determine the level of adherence to dietary recommendations in CVD management towards ascertaining the degree of knowledge and practice (to know and practice) among participants. We adapted a formula to our study according to Avira and Sabin [14]. In all, only fish, vegetable and tea/coffee recommendations recorded adherences of $50 \%$ and above, moreover the overall mean adherence was $38.31 \%$.

\section{DISCUSSION}

Nutritional adjustments and overall lifestyle changes are central to non-pharmacological management of CVD risks and CVDs. Poor dietary habits especially when accompanied with a sedentarily lifestyle accentuates CVD risk and CVD complication in the general population [7]. A hospital-based study was carried out among patients with any form of CVD in a bid to evaluate their dietary habits and in conformity with commonly recommended dietary adjustments for CVD management. 


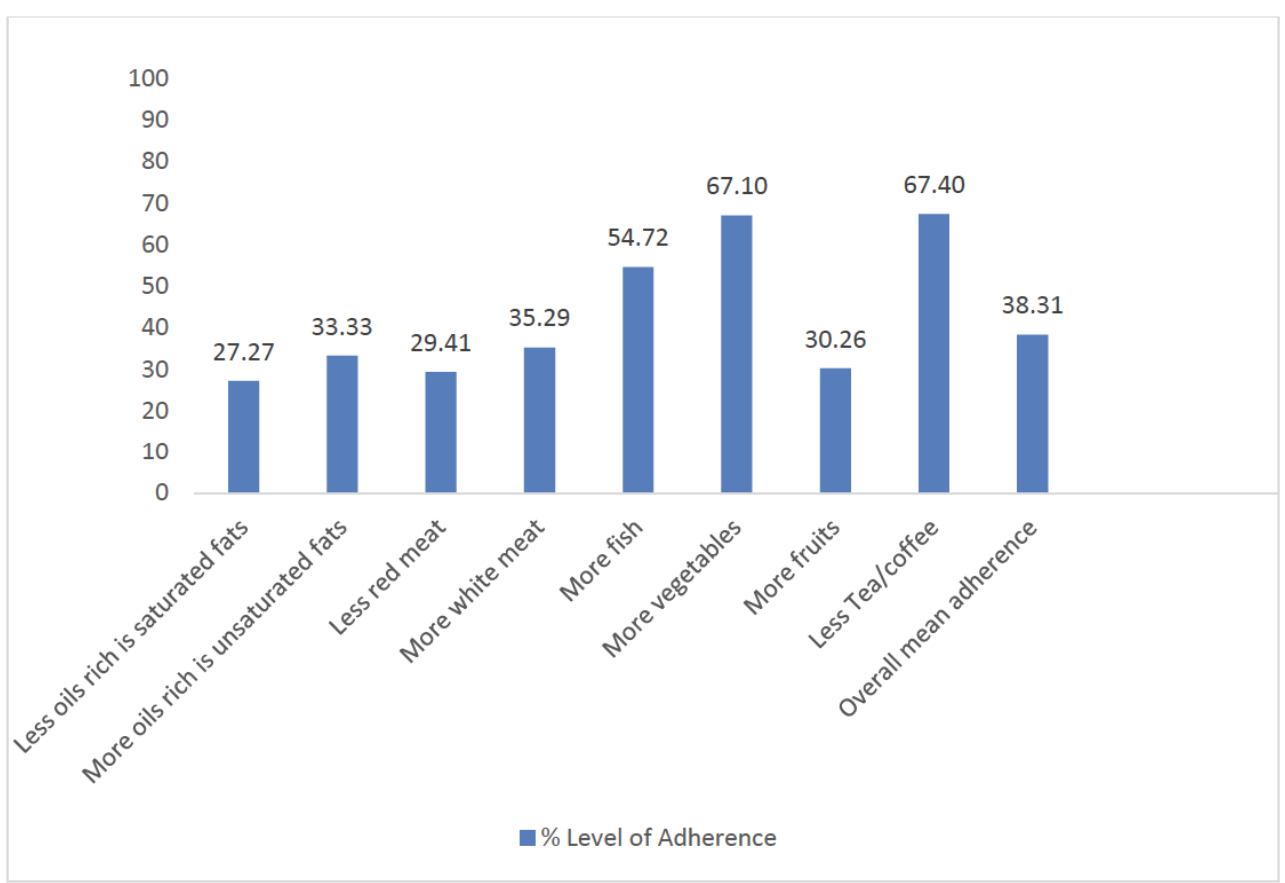

Figure 1: Level of adherence to dietary recommendations.

The study recorded high consumption rates of oils rich in saturated fatty acids $(73.64 \%)$ compared to those rich in unsaturated fats $(6.2 \%)$. At the same time, participants exhibited an elevated weekly meat consumption compared to fish consumption, with preference for red meat. $62.01 \%$ of individuals consumed meat more than twice a week compared to $13.96 \%$ of fish consumption. In the same line, $19.38 \%$ of persons consumed eggs more than thrice a week. This can be explained by the relativity and variation of food choices between persons. Also, high frequency of fish consumption (at least once a week) was observed, although few patients had dietary knowledge in this regard. It may be that, the accessibility, availability, and affordability of this commodity on the market, and individual convenience, but not the respect of dietary recommendations have contributed to the observed high frequency of fish consumption.

The Adamawa region of Cameroon is socioeconomically reputed for its dominant cattle breeding capacity, and provides for meat and other dairy products both within the country and abroad. This promotes the availability and affordability of meat and wide range of dairy products in our population [15].

Meat is an important source of proteins and lipids. The frequency of its consumption and the types consumed are vital in the management of CVD [16, 17]. Meat lipids consist mainly of saturated fatty acids favoring cholesterol synthesis, and in greater quantities compared to fish, although the composition of meat lipids, however, varies according to the type of meat. It is recommended to consume fish at a frequency of at least twice a week and to reduce or abstain from red meat consumption. A replacement with white meats, vegetable proteins and fish improves clinical outcomes in the management of patients with CVDs [17-19]. The association between fish consumption and risk of CVDs has been extensively studied. Fish are sources of omega-3 fatty acids (eicosapentaenoic and docosahexaenoic acids) which are important in preventing CVDs [20].

Eggs are foods highly rich in LDL cholesterol, and the moderation of its consumption contributes immensely in the reduction of blood cholesterol, an important parameter in the management of CVDs. In order to avoid complications due to excess serum cholesterol, egg consumption should be limited to 3 whole eggs per week [21]. Cesar et al. [21] reported that excessive intake of cholesterol altered chylomicron metabolism in young normolipaemic males while comparing cholesterol levels in egg-consuming and non-consuming individuals [22]

Fruits and vegetables are imperative in the management of CVDs by virtue of their being rich in nutrients such as soluble and insoluble fibers, phenolic compounds with antioxidant properties and minerals $[17,23]$. The level of awareness and consumption of fruits and vegetables were fairly encouraging, with 
vegetable consumption being high even when a frequency of more than 3 times weekly were considered. This may be a direct consequence of the dietary habits of the Adamawa population. In fact, vegetables are an essential part of almost all staple and traditional foods in the Adamawa region. They are widely available in large quantities on the market with a high relative affordability. In addition, more than half of the study participants were aware that the consumption of vegetables was beneficial.

Participants further portrayed a high frequency of consumption associated with a wide variability in the types of tea beverages consumed, ranging from locally grown plant leaves to commercially acquired coffee. Tea is a stimulant frequently containing catechin compounds and caffeine which affect cardiac function. High consumption of tea has a positive inotropic effect and increases the secretion of noradrenaline favoring an increase in blood pressure and heart rate. It is therefore necessary to limit its consumption to at most three cups per day in both patients with or at high risk to CVDs [16].

Investigating the association between knowledge and practice of dietary recommendations, only in the case of fish, vegetable and tea/coffee consumption the level of practice reflected the level of awareness. This in turn recorded less than $50 \%$ adherence to all the studied dietary recommendations except for fish, vegetables and tea/coffee consumption.

\section{LIMITATIONS}

The study faces major difficulties with the verification of self-reported patient data which definitely was subjected to varying levels of bias between participants although several control questions were included in our questionnaire. For instance, mild disparities were recorded between weekly and daily frequencies and the level of practice of dietary recommendations. Also, the study took into consideration the frequently consumed staple foods characteristic of the study population, but not exhaustive enough to include foreign food types.

\section{CONCLUSION}

In summary, our findings from the assessment of knowledge and practice of selected dietary recommendations in CVD management depicted under $50 \%$ awareness on all the selected dietary recommendations studied. Considering participants who responded "yes" to being aware of the dietary implications of studied variables, the levels of adherence to recommended dietary practices were under $50 \%$ in a majority of cases, with the exception of fish, vegetable, and tea/coffee consumption.

\section{PERSPECTIVES}

In view of the role of nutrition status and dietary practices in the control of CVD risk, management of CVDs and the prevention of CVD complication, many more operational research works are required to identify the factors inhibiting the respect and adherence to dietary recommendations, which can be socioeconomic, cultural, patient or caregiver related. Also randomized control trials will be imperative in formulating and adapting staple food types to internationally recommend nutritional standards, and testing their dietary potentials within selected CVD risk groups.

\section{AUTHORS CONTRIBUTIONS}

CT, OMP, MMT, conceived and designed the study.

JM, LSBB, conducted, collected and managed data.

JM, LSBB, performed the laboratory analysis

JM, LSBB, carried out the data analysis and interpretation of results.

OMP, MTT, JON, prepared the manuscript.

CT reviewed and corrected the manuscript.

\section{CONFLICT OF INTEREST}

None declared.

\section{ACKNOWLEDGEMENTS}

We commend the efforts of the staff of the Ngaoundere regional hospital for their immense practical and organizational support during the sampling of study participants. We equally appreciate the collaboration of CVD patients attending the Ngaoundere regional hospital for their medical needs and follow-up.

\section{REFERENCES}

[1] WHO, Cardiovascular diseases. Fact sheet. Reviewed September 2016. Available at http://www.who.int/ mediacentre/factsheets/fs317/en/ 
[2] Mendis S, Armstrong T, Bettcher D, Branca F, Chisholm D, Ezzati M, et al. Global Status Report on Noncommunicable Diseases 2014, WHO Library Cataloguing-in-Publication Data, Geneva, Switzerland, 2014.

[3] WHO, Global Atlas on Cardiovascular Disease Prevention and Control, World Health Organization, Geneva, Switzerland, 2011.

[4] WHO, Noncommunicable Diseases Country Profiles 2014, WHO Library Cataloguing-in Publication Data, Geneva, Switzerland, 2014.

[5] Mbouemboue OP, Tsougmo JON, Koona KA, Maha F, Kingue $S$. Place et profil évolutif des maladies cardiovasculaires en milieu hospitalier nord camerounais : le cas de l'hôpital régional de Ngaounderé. Health Sciences and Diseases 2015; 16: 1-7.

[6] Epaka EM, Mandengue SH, Ahmadou G, Moumbe TS, Dzudie A, Luma HN. Dépistage des maladies cardiovasculaires et facteurs de risque dans une cohorte de 270 camerounais: effets de l'activité physique et sportive. Médecine des Maladies Métaboliques 2011; 5: 655-658. https://doi.org/10.1016/S1957-2557(11)70342-X

[7] Violene P, Fol J, Fedora T. Immersion en milieu communautaire à Yaoundé, Cameroun 2012; www.medecine.unige.ch/.../immersion/archives/...2012/.

[8] Mbouemboue OP, Derew D, Tsougmo JON, and Tamanji MT. A Community-Based Assessment of Hypertension and Some Other Cardiovascular Disease Risk Factors in Ngaoundéré, Cameroon. International Journal of Hypertension. Article ID 4754636.

[9] Carsin M, Mahe G. Pourquoi devons-nous évaluer l'alimentation des sujets à risques vasculaires? Journal des Maladies Vasculaires 2010; 35: 17-22. https://doi.org/10.1016/j.jmv.2009.11.003

[10] Mbouemboue OP, Milamem NA, Tamanji MT, Atanga MB. Educational Needs of Hypertensive Patients in Buea Hospital Setting (Cameroon). Health Sciences and Diseases, 2015: Available at www.hsd-fmsb.org

[11] Neba A. Modern Geography of the Republic of Cameroon, 3rd ed. Bamenda: Neba Publishers, 1999.

[12] Cochran WG. Sampling Techniques, 2nd Ed., NewYork: John Wiley and Sons, Inc., 1999.
[13] Capital Health-Food and Nutrition service. Heart healthy eating tips. Dalhousie University Print Centre; 2013. Available at www.cdha.nshealth.ca

[14] Avira P, Sabin C. Medical statistics at a Glance. Edition: Black Well Science Ltd., Paris (France), 2000.

[15] PNUD-Cameroun (Programme des Nations Unies pour le Développement). (2010). Rapport régional de progrès des objectifs du millénaire pour le développement région de l'Adamaoua, 2010. www.statistics-cameroon.org/downloads/ OMD/OMD_AD_2010.pdf

[16] Dana W. Le traitement diététique de la dyslipidémie: Une approche oubliée et sous-estimée. Endocrinologie Conférences scientifiques 2006; 5: 1-6.

[17] Willett WC. Dietary fats and coronary heart disease. Journal of International Medicine 2012; 272: 13-24. https://doi.org/10.1111/j.1365-2796.2012.02553.x

[18] Boustani $F$. Les nouvelles recommandations Européennes sur la prévention des maladies cardiovasculaires en pratique clinique. Available at http://www.cardiologie-francophone. com/PDF/recommandations/recommandations-2012introduction.pdf

[19] Morozova S, Suc-royer I, Auwerx J. Modulateurs du métabolisme du cholestérol et avenir du traitement de l'athérosclérose. Medecine/Sciences 2004; 20: 685-690. https://doi.org/10.1051/medsci/2004206-7685

[20] Sang MK, Seung-Kwon M, Young JL, Hong GS. Efficacy of Omega-3 Fatty Acid Supplements (Eicosapentaenoic Acid and Docosahexaenoic Acid) in the Secondary Prevention of Cardiovascular Disease: A Meta-analysis of Randomized, Double-blind, Placebo-Controlled Trials. Archive of Internal Medicine 2012; 179: 686-694.

[21] Cesar TB, Oliveira MR, Mesquita $\mathrm{CH}$, Maranhão RC. High cholesterol intake modifies chylomicron metabolism in normolipidemic young men. Journal of Nutrition 2006; 136 : 971-976.

[22] Vanhoutte EL. Prise en charge nutritionnelle du patient hypertendu. Thèse en science pharmaceutique, Université Joseph Fourier (France) 2013; Available at https://dumas.ccsd.cnrs.fr/dumas-00798577/document 